\title{
BIOEQUIVALENCE STUDY ON TWO BRANDS OF 10\% ENROFLOXACIN ORAL FORMULATIONS IN CHICKENS
}

\author{
GBERINDYER $^{1}$, F. A., WANNANG ${ }^{2}$, N. N. and AKWUOBU ${ }^{3}$, C. A. \\ ${ }^{1}$ Department of Veterinary Physiology and Pharmacology, University of Agriculture, \\ Makurdi, \\ ${ }^{2}$ Department of Pharmacology, University of Jos, \\ ${ }^{3}$ Department of Veterinary Pathology and Microbiology, University of Agriculture, \\ Makurdi, Nigeria. \\ * Corresponding author: Email: chineduakwuobu@yahoo.com;
}

Tel: $+\mathbf{2 3 4 8 0 3 7 7 8 7 7 0 6}$

\section{SUMMARY}

A bioequivalence of two brands of $10 \%$ enrofloxacin was tested in broiler chickens using a parallel design at $20 \mathrm{mg} / \mathrm{kg}$ bodyweight orally. Blood was sampled before and after drug administration for $\mathbf{2 4}$ hours. Plasma enrofloxacin concentrations were analyzed using microbiological assay. Peak plasma concentrations $\left(\mathrm{C}_{\max }\right), 1.00 \pm 0.05$ and $0.91 \pm 0.02 \mu \mathrm{g} / \mathrm{ml}$ were obtained in chickens given Reference and Test brands respectively at $1.00 \pm 0.01$ and $2.00 \pm$ 0.17 hours respectively. Areas under plasma concentration-time curve (AUC024) were $3.79 \pm 0.07$ and $4.90 \pm 0.01 \mu \mathrm{g} / \mathrm{ml}$ for Reference and Test brands respectively. Ratios of $\mathrm{C}_{\text {max }}$, and $\mathrm{AUC}_{0-24}(\mathrm{~T} / \mathrm{R})$ were 0.91 and 1.29 respectively. These are within the bioequivalence acceptance range. conflox ${ }^{\circledR}$-vet and kenflox ${ }^{\circledR}$ are therefore bioequivalent and interchangeable.

Key words: Antibacterial, Bioequivalence, Enrofloxacin, Plasma.

\section{INTRODUCTION}

Enrofloxacin is a third generation, synthetic and broad spectrum bactericidal Fluoroquinolone exclusively used in veterinary medicine (Sheer, 1990; Vancutsem et al., 1990). It has an excellent antibacterial activity against most pathogenic bacterial organisms that are resistant to other antibacterial agents (Bauditz, 1987; Elmas et al., 2000).

Pharmacokinetic studies have indicated that enrofloxacin is rapidly absorbed and well distributed throughout the body following oral and intramuscular administrations in animals (Soliman, 2000; Randall et al., 2006). This supports its frequency of use in treating avian invasive infectious diseases like fowl typhoid, colibacillosis, pasteurollosis and mycoplasmosis. Most brands of enrofloxacin have been demonstrated not to be bioequivalent with the innovator formulation in animal studies conducted outside Nigeria on the formulations available in such places (Sumano et al., 2001a; Sumano et al., 2006).

There are arrays of multisource brands of enrofloxacin in the market. Most of these brands do not give the desired therapeutic outcome when compared with the pioneer product $\left(\right.$ baytril ${ }^{\circledR}$ ) 
which is not available currently in the Nigerian market. The significance of enrofloxacin in veterinary medicine and lack of documented blood-level bioequivalence evaluation of the abundant imported brands in Nigeria has informed this study.

\section{MATERIALS AND METHOD Study Products}

Kenflox $^{\circledR} \quad(10 \%$ enrofloxacin $)$ from Holland (Batch No. 0811703, Exp. 032011) was used as test brand while conflox-vet $^{\circledR}$ (10\% enrofloxacin) from India (Batch No. 70002, Exp. 06-2012) was used as the reference brand due to its widespread availability and effectiveness. Pure enrofloxacin $(\geq$ 98\%) from Sigma- Aldriech, USA was used as a standard.

\section{Experimental Subjects}

Twenty four broiler chickens, 8 weeks old, weighing $2.5-3.0 \mathrm{~kg}$ body weights (b.w) were used. Fifty day-old broiler chicks were commercially sourced and managed under deep litter system. They were vaccinated against most common infectious poultry diseases. The feed was formulated without inclusion of drugs. At 5 weeks old, the apparently healthy chickens (24 chickens) were separated and allowed to acclimatize in the experimental environment for three weeks during which no drug, except multivitamins was administered to them.

\section{Experimental Design}

A randomized, single oral dose and parallel method was employed. The animals were assigned to two groups, A-reference and B-test $(n=12)$. Feeds and water were withdrawn 8 and 2hours respectively before drug administration. This was to reduce absorption variability due to drug-feed interaction and over dilution of the drug respectively (Randandt et al.,
1992). Animals in each group were weighed individually and their dosages calculated based on weights $(20 \mathrm{mg} / \mathrm{kg}$ b.w). Group A was administered the reference drug (conflox-vet ${ }^{\circledR}$ ) while animals in group B were given the test brand $\left(\right.$ kenflox $\left.^{\circledR}\right)$. The drugs were given per os using an improvised oral canula attached to a $5 \mathrm{ml}$ syringe. The animals were monitored and those that regurgitated were excluded from the experiment. Thereafter, feeds and water were re-introduced 2 hours post drug administration.

\section{Sampling and Processing}

Blood samples were obtained by venipuncture through the left or right brachial veins into EDTA tubes at times 0 (pre treatment), $0.25,0.5,1,2$, $3,4,6,8,10,12$, and 24 hours (post treatment). It was ensured that the differences between the targeted and the actual sampling times were not more than 2 minutes. The samples were centrifuged at $3000 \mathrm{rpm}$ for 10 minutes at $37^{\circ} \mathrm{C}$ and the supernatant (plasma) collected into plastic microtubes. These were stored at $-4{ }^{\circ} \mathrm{C}$ and analyzed 24 hours following sampling.

\section{Plasma Analysis of Enrofloxacin}

A quantitative-qualitative agar diffusion microbiological assay using blank disks $(7 \mathrm{~mm})$ was employed (Kwasi et al., 1999; Ehab et al., 2008; Andres et al., 2009). This assay is based on the concentration-dependent variation of the inhibitory effect of antibiotics on a test bacterium, producing a concentration-response (zone of inhibition) linear relationship. The test organism used was Escherichia coli, NCTC10418 on nutrient agar medium ((Bryant, 1981; Dowling et al., 1995).

Briefly described, the blank disks were adequately saturated with enrofloxacin-spiked blank and treated plasma samples separately. The 
impregnated disks were then carefully and firmly placed onto the surface of the E.coli-seeded nutrient media Petri dishes $(n=3)$. This was allowed to stand for 5 minutes to allow for diffusion, after which they were incubated at $37^{\circ} \mathrm{C}$ overnight in an aerobic condition. Thereafter, the diameters of inhibition zones were measured with the aid of a transparent rule to the nearest millimeter. Each sample was replicated thrice and analyzed similarly.

A seven-point standard curve was constructed by spiking blank chicken plasma with concentrations of analytical enrofloxacin ranging from 0.02 to $5.00 \mu \mathrm{g} / \mathrm{ml}$. The plot of enrofloxacin plasma concentrations versus diameters of inhibition zone was linear with a correlation coefficient of 0.89 . Plasma concentrations of enrofloxacin were determined by comparing the zone of inhibition diameters with the standard curve. The absence of interfering endogenous compounds was demonstrated in antibacterial-free plasma obtained at time 0 (pretreatment) which showed no visible zone of inhibition around the impregnated disks. The limit of quantification (LOQ) defined visually as the smallest amount of drug that still produced a clearly distinguishable inhibition zone around the edges of enrofloxacin-saturated disks on nutrient agar media was $0.02 \mu \mathrm{g} / \mathrm{ml}$ ((Andres et al., 2009).

\section{Pharmacokinetics and Statistical Analyses}

Plasma concentrations of enrofloxacin versus time data obtained during the study were utilized for calculating various pharmacokinetic variables using a non-compartmental analysis. The peak concentrations, $\mathrm{C}_{\max }$ and time to peak, $\mathrm{T}_{\max }$ were obtained from the plasma concentration-time data directly. The areas under the plasma concentration of enrofloxacin time curves from time 0 to the last sample collected $\left(\mathrm{AUC}_{0-24}\right)$ were calculated using linear trapezoidal method (Baggot, 2001). While $\mathrm{AUC}_{0-\infty}$ was derived from $\mathrm{AUC}_{0-24}+\mathrm{AUC}_{24-\infty}$, where $A C_{24-\infty}=C_{24} / B$. For bioequivalence evaluation, the ratios of $\mathrm{C}_{\max }(\mathrm{T} / \mathrm{R}), \mathrm{AUC}_{0-24}(\mathrm{~T} / \mathrm{R})$ and $\mathrm{AUC}_{0-\infty}$ $(T / R)$ were calculated. Values within the bioequivalence acceptable range at $90 \%$ confidence interval, $0.80-1.25$ were considered for accepting the null hypothesis of bioequivalence between the reference and the test brands ((EMEA, 2006).

Statistical analysis on the plasma concentration-time and pharmacokinetic profiles were carried out with two-way analysis of variance (ANOVA). Significant difference at $p$ $<0.05$ was determined using Dunett test. All data were reported as mean \pm SEM.

\section{RESULTS}

The composite data and curves depicting the mean plasma concentrations (mean \pm SEM) of enrofloxacin versus time following oral administration of confloxvet $^{\circledR}$ and kenflox ${ }^{\circledR}$ brand at the dose level of $20 \mathrm{mg} / \mathrm{kg}$ b.w to broiler chickens are presented in Table $I$ and Figure 1 respectively.

The mean plasma concentrations-time profiles for the two pharmaceutical formulations were dissimilar throughout the time of sampling. But the mean plasma concentrations of enrofloxacin in all the groups were never below the reported minimum inhibition concentration $(0.008-0.06 \mu \mathrm{g} / \mathrm{ml})$ for the common pathogenic bacterial organisms of avian species (Sanjib et al., 2005). The mean maximum plasma concentration of enrofloxacin, $\mathrm{C}_{\max }$ in animals given the conflox-vet ${ }^{\circledR}$ and 
kenflox ${ }^{\circledR}$ formulations were $1.00 \pm 0.05$ and $0.91 \pm 0.02 \mu \mathrm{g} / \mathrm{ml}$ respectively. While the time to attain these peak concentrations $\left(\mathrm{T}_{\max }\right)$ were 1 and 2 hours respectively.

Based on the number of linear decay components in the mean plasma concentration of the drug versus time data plotted on a semi-logarithmic scale over 24 hour period for the two brands, a two compartment open-model was selected to describe the plasma disposition kinetics of enrofloxacin in broiler chickens. The general biexponential equation fitted to the mean plasma concentration versus time data for the two formulations was $\mathrm{C}_{(\mathrm{t})}=\mathrm{Ae}^{-}$ $\mathrm{k} \alpha(\mathrm{t})+\mathrm{Be}^{-\mathrm{k} \beta(\mathrm{t})}$, where A and B represent intercepts on the $\mathrm{y}$-axis; $\mathrm{C}_{(\mathrm{t})}$ is the mean plasma concentration at time $\mathrm{t}$; $-\mathrm{k} \alpha$ is the estimated first-order rate constant of absorption, $-\mathrm{k}_{\beta}$ is the estimated firstorder rate constant of elimination of the drug.

The statistical analysis of the pharmacokinetic variables that describes the rate $\left(\mathrm{C}_{\max }\right)$ and extent of absorption (AUC) of enrofloxacin are presented in Table II. While the data depicting the bioequivalence point estimates and the acceptable range at $90 \%$ confidence interval is presented in Table III. The calculated value for $\mathrm{C}_{\max }(\mathrm{T} / \mathrm{R}), \mathrm{AUC}_{0-24}$ $(\mathrm{T} / \mathrm{R})$ and $\mathrm{AUCo}-\infty(\mathrm{T} / \mathrm{R})$ were 0.91, 1.29 and 1.29 respectively.

All the experimental animals remained healthy during and after the study.

\section{DISCUSSION}

The effectiveness of a drug is partly dependent on its formulation, route of administration and metabolic pattern (Alvinerie et al., 1999). These factors determine the plasma concentration-time profile of the drug. Following administration of a single oral dose (20 $\mathrm{mg} / \mathrm{kg} \quad$ b.w) of $10 \%$ enrofloxacin formulations to healthy broiler chickens, therapeutic concentration were achieved 15 minutes post administration in all the animals. The concentration was detected up to 10 and 12 hours in the plasma of chickens given the conflox-vet ${ }^{\circledR}$ and kenflox ${ }^{\circledR}$ brands respectively. Although there was a significant difference $(\mathrm{p}<$ 0.05 ) in mean plasma concentrations of enrofloxacin between the two groups, the plasma concentrations at all time points in both groups were 10 fold higher than the minimum inhibition concentration, $\mathrm{MIC}_{90}$ reported for enrofloxacin in chickens against most pathogenic bacterial organisms in avian species (Sanjib et al., 2005).

This suggests that the two brands when given at this dose will be clinically effective and there will be reduced chances of the emergence of resistant bacterial strains (Drusano, 1993; Baggot, 2001). Differences in the formulation of the drugs could be responsible for the significant difference in the mean plasma concentrations of enrofloxacin between the two brands. 
Table I. Mean plasma concentrations of enrofloxacin $(\mu \mathrm{g} / \mathrm{ml})$ in broiler chickens following oral administration of conflox-vet ${ }^{\circledR}$ (reference) and kenflox ${ }^{\circledR}$ (test) formulations at a dose level of $20 \mathrm{mg} / \mathrm{kg}$ b.w Values are mean $\pm \operatorname{SEM}(\mathrm{n}=12)$

\begin{tabular}{|c|c|c|c|}
\hline \multirow[b]{2}{*}{$\begin{array}{l}\text { Time post } \\
\text { Administration (hour) }\end{array}$} & \multicolumn{2}{|c|}{ Mean plasma concentration $(\mu \mathrm{g} / \mathrm{ml})$} & \multirow[b]{2}{*}{$\%$ change } \\
\hline & $\begin{array}{l}\text { Conflox-vet }^{\circledR} \\
\text { (Reference) }^{\text {Reference }}\end{array}$ & Kenflox $^{\circledR}$ (Test) & \\
\hline 0.25 & $0.38 \pm 0.018$ & $0.13 \pm 0.023$ & 65.79 \\
\hline 0.50 & $0.77 \pm 0.035$ & $0.61 \pm 0.035$ & 20.78 \\
\hline 1.00 & $1.00 \pm 0.055$ & $0.83 \pm 0.038$ & 17.00 \\
\hline 2.00 & $0.86 \pm 0.030$ & $0.91 \pm 0.024 *$ & 5.00 \\
\hline 3.00 & $0.65 \pm 0.020$ & $0.84 \pm 0.035$ & 29.23 \\
\hline 4.00 & $0.42 \pm 0.027$ & $0.54 \pm 0.035^{*}$ & 12.00 \\
\hline 6.00 & $0.19 \pm 0.036$ & $0.24 \pm 0.038$ & 26.32 \\
\hline 8.00 & $0.12 \pm 0.025$ & $0.17 \pm 0.025$ & 41.67 \\
\hline 10.00 & $0.09 \pm 0.000$ & $0.14 \pm 0.018$ & 55.56 \\
\hline 12.00 & ND & $0.11 \pm 0.000$ & NA \\
\hline 24.00 & ND & ND & NA \\
\hline
\end{tabular}

NB: $\quad$ Values are mean \pm SEM $(n=12)$; *The mean difference is significant at the $p<$ 0.05 level from those of reference drug; Not detected (ND) and not applicable (NA)

Table II. Mean pivotal pharmacokinetic parameters of bioequivalence testing for two oral formulations of $10 \%$ enrofloxacin

\begin{tabular}{lcc}
\hline Pharmacokinetic Parameter & \multicolumn{2}{c}{ Brand } \\
\cline { 2 - 3 } & $\begin{array}{c}\text { Conflox-vet }^{\circledR} \\
\text { (Reference) }\end{array}$ & Kenflox $^{\circledR}$ (Test) \\
$\mathrm{C}_{\max }(\mu \mathrm{g} / \mathrm{ml})$ & $1.00 \pm 0.055$ & $0.91 \pm 0.024$ \\
$\mathrm{AUC}_{0-24}(\mu \mathrm{g} . \mathrm{h} / \mathrm{ml})$ & $3.79 \pm 0.072$ & $4.90 \pm 0.007 *$ \\
$\mathrm{AUC}_{0-\infty}(\mu \mathrm{g} . \mathrm{h} / \mathrm{ml})$ & $4.35 \pm 0.072$ & $5.59 \pm 0.007 *$ \\
\hline
\end{tabular}

NB: Values are mean \pm SEM $(n=12)$. *The mean difference is significant at the $p<0.05$ level from those of the reference drug

Table III. Bioequivalence ratio of test and reference brands of $10 \%$ enrofloxacin oral formulations

\begin{tabular}{|c|c|c|c|}
\hline & $C_{\max }(\mu \mathrm{g} / \mathrm{ml})$ & $\mathrm{AUC}_{0-24}(\mu \mathrm{g} . \mathrm{h} / \mathrm{ml})$ & $\mathrm{AUC}_{0-\infty}(\boldsymbol{\mu g} \cdot \mathbf{h} / \mathrm{ml})$ \\
\hline Reference $\left(\right.$ conflux-vet $\left.{ }^{(B)}\right)$ & $1.00 \pm 0.06$ & $3.79 \pm 0.07$ & $4.35 \pm 0.07$ \\
\hline Test $\left(\right.$ kenflox $\left.^{(B)}\right)$ & $0.91 \pm 0.02$ & $4.90 \pm 0.07$ & $5.59 \pm 0.07$ \\
\hline Point estimate & 0.91 & 1.29 & 1.29 \\
\hline Acceptable range & $0.80-1.25$ & $0.80-1.25$ & $0.80-1.25$ \\
\hline Conclusion & $\mathrm{BE}$ & $\mathrm{BE}$ & $\mathrm{BE}$ \\
\hline
\end{tabular}

BE-Bioequivalence 


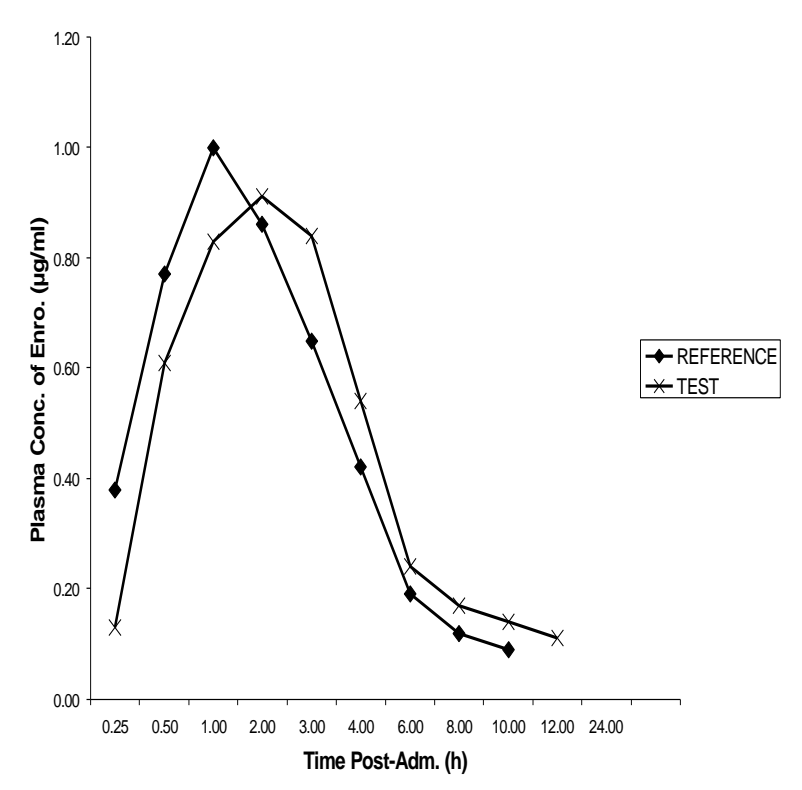

Figure 1. Plasma concentration-time profile curves of enrofloxacin after oral administration of reference (confloxvet $\left.^{\circledR}\right)$ and test $\left(\right.$ kenflox $\left.^{\circledR}\right)$ brands in broiler chickens (20 mg/kg b.w).

The bi-exponential equation, $\mathrm{C}_{(\mathrm{t})}=\mathrm{Ae}^{-}$ $\mathrm{k \alpha}(\mathrm{t})+\mathrm{Be}^{-\mathrm{k} \beta(\mathrm{t})}$ described the plasma disposition kinetics of enrofloxacin in all the experimental subjects used. This implies that the pharmacokinetic of enrofloxacin following a single oral administration to broiler chicken at the dose level of $20 \mathrm{mg} / \mathrm{kg}$ b.w can be described by a two compartmental openmodel. This is in agreement with the previous studies in birds, chickens, rabbits, dogs and ruminants (Broome et al., 1991; Flammer et al., 1991; Walker et al., 1992; Anadon et al., 1995; Kwasi et al., 1999; Elmas et al., 2004).

Although there was no significant difference $(p>0.05)$ between the two groups, the mean plasma concentrations $\left(\mathrm{C}_{\max }\right)$ of enrofloxacin in the animals given Conflox-Vet ${ }^{\circledR}$ formulation $(1.00 \pm$ $0.004 \mu \mathrm{g} / \mathrm{ml}$ ) was higher than those administered Kenflox ${ }^{\circledR}(0.91 \pm 0.024$ $\mu \mathrm{g} / \mathrm{ml})$. These values are considerably lower than those reported earlier in broiler chickens at a dose level of 10 mg/kg (Anadon et al., 1995; DaSilva et al., 2006; Posyniak et al., 2007). But the mean $\mathrm{C}_{\max }$ in the present study is similar to those earlier reported in chickens $(0.99 \pm 0.08 \mu \mathrm{g} / \mathrm{mg})$ (Kwasi et al., 1999). The time taken to attain the peak plasma concentration, $\mathrm{T}_{\max }$ of enrofloxacin was shorter in chickens administered conflox-vet $^{\circledR}$ (1 hour) than the group given kenflox ${ }^{\circledR}$ brand (2 hours).

The area under the drug concentrationtime curve (AUC) is a useful index for biological availability of the active moiety of a drug formulation (extent of absorption). In the present study, the mean $\mathrm{AUC}_{0-24}$ and $\mathrm{AUC}_{0-\infty}$ values for the two brands were significantly different $(p<0.05)$. The mean value observed in animals given kenflox ${ }^{\circledR}$ formulation $(4.90 \pm 0.01 \mu \mathrm{g} . \mathrm{h} / \mathrm{ml})$ is higher than that obtained in the group administered brand conflox-vet ${ }^{\circledR}(3.79 \pm$ $0.07 \mu \mathrm{g} . \mathrm{h} / \mathrm{ml})$. This is likely due to differences in formulations. The mean values of $\mathrm{AUC}_{0-24}$ obtained in this study are both higher and lower than or similar to values obtained earlier in broiler chickens (Knoll et al., 1999; Haritova et al., 2004; DaSilva et al., 2006). The differences are likely due to variations in the formulations used, dosages and routes of administrations. The mean values of $\mathrm{AUC}_{0-24}$, and $\mathrm{AUC}_{0-\infty}$ for the two brands used in this study were significantly different $(\mathrm{p}<0.05)$, suggesting that enrofloxacin plasma concentration-time profile produced by the two brands are not the same. This could explain the significant difference 
in the mean plasma concentration-time profile observed between the two groups.

Bioequivalence refers to a comparison between generic formulations of a drug, or a product in which a change has been made in one or more of the ingredients or in the manufacturing process, and a reference dosage form of the same drug (Alvinerie et al., 1999). This study shows that the bioequivalence ratio for mean $\mathrm{AUC}_{0-24}, \mathrm{AUC}_{0-\infty}$ and $\mathrm{C}_{\max }(\mathrm{T} / \mathrm{R})$ of kenflox ${ }^{\circledR}$ versus the reference products were $1.29,1.29$ and 0.91 respectively. These values were within the recommended range at the level of $90 \%$ confidence interval, $0.80-1.25$ (Walker et al., 1992). The two brands of $10 \%$ enrofloxacin oral tested in this experiment could therefore be considered bioequivalent.

\section{CONCLUSION}

Since AUC reflects the access of enrofloxacin to the blood circulation (bioavailability), all the formulations seemed to be well absorbed after oral administration. The dosage regimen used in this study is sufficient to maintain an effective therapeutic plasma concentration of enrofloxacin when any of the two brands studied is used in broiler chickens. But the test formulation, $\operatorname{kenflox}^{\circledR}$ is superior in terms of maintaining therapeutic concentration over a long time. Since bactericidal activity of Fluoroquinolones is concentration-dependent but not time dependent, the in vivo performance of these brands is anticipated to be equivalent (Craig, 1993; Baggot, 2001). The test formulation, kenflox $^{\circledR}$ by KEPRO BV, Holland is therefore bioequivalent to our reference product, conflox ${ }^{\circledR}$-vet by Concept pharmaceuticals, India. The two brands can be substituted for one another in avian medicine.

\section{REFERENCES}

ALVINERIE, M., LACOSTE, E., SUTRA, J.F. and CHARTIER, C. (1999): Some pharmacokinetic parameters of Eprinomectin in goats following pour-on Administration. Vet. Res. Comm., 23: 449-455.

ANADON, A., MARTINEZLARRANAGA, M.R., DIAZ, M.J., BRINGAS, P., MARTINEZ, M.A., FERNANDEZ-CRUZ, M.L. and FERNANDEZ, R. (1995): Pharmacokinetics and residues of enrofloxacin in chickens. Am. J. Vet. Res., 56 (4): 501-506.

ANDRES, F.G., MARIA, A., CARLOS, A.R. and OMAR, V. (2009): Application of microbiological assay to determine pharmaceutical equivalence of generic intravenous antibiotics. BMC Clin. Pharmacol., 9: 1 11.

BAGGOT, J.D. (2001): The physiological Basis of veterinary clinical pharmacology. $1^{\text {st }} \mathrm{ed}$. Blackwell, London.

BAUDITZ, R. (1987): Results of clinical studies with Baytril ${ }^{\mathrm{TM}}$. Poult. Vet. Med. Rev., 2: 130-136.

BROOME, R.L., BABISH, G.I., COPELAND, D.D. and CONZELMAN, G.M. (1991): Pharmacokinetic properties of enrofloxacin in rabbits. Am. $J$. Vet. Res., 52: 1835-1841.

BRYANT, M.C. (1981): The assay of Antibiotics in Body Fluids. In: Laboratory Control of Antibacterial Chemotherapy. $1^{\text {st }}$ ed. London: John Wright; pp. 102-123. 
CRAIG,

W.A.

(1993):

Pharmacodynamics

of

antimicrobial agents as a basis for determination dosage regimens. Euro. J. Clin. Microbiol. Infect. Dis., 1: 6-8.

DASILVA, R.G., REYES, F.G.R., SARTORI, J.R. and RATH, S. (2006): Enrofloxacin assay validation and pharmacokinetics following a single oral dose in chickens. J. Vet. Pharmacol. Therapeut., 29 (5): 365-372.

DOWLING, P.M., WILSON, R.C., TYLER, J.W. and DURAN, S.H. (1995): Pharmacokinetics of Ciprofloxacin in Ponies. J. Vet. Pharmacol. Therap., 18: 7 - 12 .

DRUSANO, G.L.

(1993): Pharmacodynamics of a Fluoroquinolone antimicrobial agent in a neurotropic rat model of Pseudomonas sepsis. Antimicrob. Ag. Chemother., 37: 483-490.

EHAB, B., SAAD, M.G., ALAELDEIN, M.A., AHMAD, F.S. and AHMAD, M.A. (2008): Pharmacokinetics and Bioequivalence of two norfloxacin oral dosage forms (Vapcotril-10\% ${ }^{\circledR}$ and Mycomas ${ }^{\circledR}$ $10 \%{ }^{\circledR}$ ) in Healthy Broiler chickens. Intern. J. Poult. Sci., 7 (3): 289-293.

ELMAS, M., YAZAR, E., TRAS, B., BAS, A.L. and ERYAVUZ, A. (2000): Pharmacokinetics and oral Bioavailability of enrofloxacin in faunated and defaunated Angora goats. Revue Med. Vet., 6 (151): 507-510.

EMEA. (2006): The European Agency for Evaluation of Medicinal Products. Questions and Answers on Bioavailability and Bioequivalence Guidance.

FLAMMER, K., AUCOIN, D.P. and WHITT, D.A. (1991): Intramuscular and oral disposition of enrofloxacin in African grey parrots following single and multiple doses. J. Vet. Pharmacol. Therapeut., 14: 359366.

HARITOVA, A., DJENEVA, H., LASHEV, L., SOTIROVA, P., GYUROV, B. and STEFANOVA, M. (2004): Pharmacokinetics and PK/PD modeling of enrofloxacin in Meleagris Gallopavo and Gallus Domesticus. Bulg. J. Vet. Med., 7 (3): 139-148.

KNOLL, U., GLUNDER, G. and KIETZMANN, M. (1999):

Comparative study of the plasma pharmacokinetics and tissue concentrations of danofloxacin and enrofloxacin in broiler chicken. J. Vet. Pharmacol. Therapeut., 22 (4): 239-246.

KWASI, B., BLACK, W.D. and SCOTT, M.E. (1999):. Pharmacokinetics of enrofloxacin given by oral, intravenous and intramuscular routes in broiler chickens. Canad. J. Vet. Res., 63: 193-200.

POSYNIAK, A., ZAMUDZKI, J., NIEDDZIELSKG, J. and BIERNACKI, B. (2007): Bioequivalence study of two formulations of enrofloxacin following oral administration in chickens. Bull. Vet. Res. Inst. Pulawy., 45 (2): 353- 358.

RANDALL, L.P., COOLES, S.W., COLDHAM, N.C., STAPELTON, K.S., PIDDOCK, 
L.J.V. and WOODWARD, M.J. (2006): Modification of enrofloxacin treatment Regimes for poultry experimentally infected with Salmonella enterica serovar Typhimurium DT104 to minimized selection of Resistance. J. Antimicrob. Ag. Chemother., 50 (12): 4030-4037.

RANDANDT, K.M., RANDALL, M.C. and DUDLEY, M.N. (1992): Interactions of Fluoroquinolones with other drugs: Mechanisms, variability, clinical significance, and management. Clin. Infect. Dis., 14: 272-284.

SANJIB, K., CHANDANA, C.B., PRITAM, M. and MOHAN, B. (2005): Pharmacokinetics studies of enrofloxacin in Yak after intramuscular administration. Ir. J. Pharmacol. Therap., 4(2): 91 -94 .

SCHEER, M. (1987): Concentrations of active ingredient in serum and tissues after oral and parenteral administration of Baytril. Vet. Med. Rev., 2: 104 - 118.

SOLIMAN, G.A. (2000): Tissue distribution and disposition kinetics of enrofloxacin in healthy and E. coli infected broilers. Dtsch Tierarztl Wochenschr, 107 (1): 23 - 27.

SUMANO, L.H., GUTIERREZ, O.L. and ZAMORA, M.A. (2001): Bioequivalence of farm preparations of enrofloxacin in poultry. J. Vet. Pharmacol. Therapeut., 24 (5): 309 - 313.

SUMANO, L.H., LILIA, G. and LUIS, O. (2006): Bioequivalence Comparison of 17 commercial oral enrofloxacin against the original pioneer preparation in broilers. J. Poult. Sci., 43: 23-28.

VANCUTSEM, M., BABISH, J.G. and SCHWARK, W.S. (1990): The Fluoroquinolone antimicrobials: structure, antimicrobial activity, pharmacokinetics, clinical use in domestic animals and toxicity. Corn. Vet., 80: 173-186.

WALKER, R.D., STEIN, G.E., HAUPTMAN, J.G. and MACDONALD, K.H. (1992): Pharmacokinetics evaluation of enrofloxacin administered orally to healthy dogs. Am. J. Vet. Res., 53: $2315-2319$. 